\title{
DISCURSO TENTATIVO SOBRE \\ O ANONIMATO
}

\author{
Ana Clara Torres Ribeiro \\ Alice Lourenço
}

\begin{abstract}
Resumo. O artigo interroga, associando-as à crise societária, as formas atuais de nomeação e classificação social que procuram organizar intervenções referidas aos denominados excluídos. Trata, com especial ênfase, a produção social do anonimato, enfatizando sentidos sociais da ação estratégica focalizada, que caracteriza políticas públicas e a competitividade entre agentes econômicos. Para tal, recorre a orientações reflexivas da filosofia e da sociologia e a um conjunto heterogêneo de fontes documentais. $\mathrm{O}$ artigo alerta para os limites contemporâneos da socialidade e do autoritarismo, que se ocultam nas formas correntes de nomeação do não-outro.
\end{abstract}

Palavras-chave. interação social, classificação social, cultura, desigualdade

O corpo do negro foi levado no banguê, jogado na vala, muito fuçada de porcos e procurada pelos cachorros da cidade, no cemitério dos escravos que os urubus atentos vigiavam e donde, conforme dava o vento, vinha um cheiro de podridão. Esse cemitério era pra baixo do campo da Forca, nuns desbarrancados, atrás da igreja da Abadia. (Cora Coralina. O tesouro da casa velha).

\section{Primeira abertura: sobre discurso}

Na pretensão de construir um discurso sobre o anonimato, sempre existe o risco de atribuir coerência analítica ao que não tem sentido, por

Ana Clara Torres Ribeiro é socióloga, doutora em Ciências Humanas pela Universidade de São Paulo; professora do Instituto de Pesquisa e Planejamento Urbano e Regional (IPPUR/UFRJ); pesquisadora $\mathrm{CNPq}$.

Alice Lourenço é socióloga, graduada pela Universidade Federal do Rio de Janeiro (UFRJ); bolsista de apoio técnico do CNPq. 
não constituir um âmbito de investimentos culturais significativos e, portanto, de representações sociais consistentes. Também existe o risco de que a introdução de conceitos e saberes disciplinares em universos socialmente distantes do pesquisador termine por oferecer um retrato de tintas exageradas ou, pior, excessivamente sutis e abstratas. ${ }^{1}$ Além disto, como previne Foucault (1996), o discurso analítico sempre encontra-se delimitado por interdições e regras advindas do controle institucional da palavra, o que atinge o enunciado de questões de formas por vezes desconhecidas, até mesmo para aquele que o pronuncia. Porém, o discurso analítico configura uma obrigação do cientista social, mesmo que, no cumprimento desta obrigação, o próprio analista se veja obrigado a enfrentar a esfinge da complexidade e, não, a ordenação racional de dilemas do presente.

Este discurso resiste ao atual predomínio das imagens e metáforas, por exigir uma determinada costura de idéias que expõe o seu formulador no mesmo movimento em que são realizadas clivagens, ou melhor, recortes nos possíveis significados, e variáveis internas, do fenômeno estudado. Mais do que a constatação do anonimato, este texto volta-se para a produção social de anônimos, como fenômeno sintomático do "estado da sociedade". Nesta escolha, permanecem existindo incertezas, mesmo que os traços mais gerais do ensaio tenham dependido da certeza axiomática de que a produção social de anônimos toca no fundo societário da formação social brasileira, assim como, nos agenciamentos que particularizam, nesta formação, os atuais comandos da economia globalizada.

Sem dúvida, imagens e metáforas têm sido acionadas, na fase contemporânea do capitalismo, na denúncia da exclusão, assim como, na difusão do denominado pensamento único (Barsted, 1999). Porém, cabe a nós repeti-las, mimetizando a mídia e os governos, ou tentar apreender o não-outro na formulação de questões do presente? Acreditamos que, para o analista, não existam muitas opções, além da tentativa de interrogar a atualização de velhos processos societários e de identificar aqueles outros processos que podem ser efetivamente reconhecidos como novos novíssimos, como propõe Milton Santos (1996). 
Este texto foi concebido de forma estranha e árdua, já que parte de uma intuição em direção a possibilidades de demonstração de um fenômeno negativo - o não-ser, o não-outro, o nada. Evidentemente, teria sido possível recorrer, com este intuito, à vasta temática contemporânea da exclusão social. Porém, queríamos atingir algo mais radical, envolto no ocultamento e no desaparecimento. Com esta vontade, elencamos, de início, alguns espaços e tempos sociais que orientariam a pesquisa do não-outro: asilos, orfanatos, enterros de indigentes, cadáveres sem identificação. Esta tem sido uma pesquisa difícil, por comprometer o pesquisador com o que se encontra atrás (em qual temporalidade e espacialidade?) do tecido social mais aparente, hoje espetacularizado.

Os obstáculos a este tipo de pesquisa são muitos, já que se trata de investigar uma plêiade de processos envolvidos na produção social do esquecimento e da invisibilidade. Como desvendar os seus espaços e tempos? De fato, opõe-se, ao desvendamento desejado, o desinteresse pela produção da informação organizada, como demonstram as dificuldades no acesso ao número de cadáveres de indigentes no Instituto Médico Legal do Rio de Janeiro e de dados relativos às características individuais daqueles que buscam obter, na idade adulta, documentos de identidade nos postos da cidadania da Baixada Fluminense. Não existem estatísticas de fácil acesso, portanto, mesmo que as estatísticas não permitam, em geral, ir ao âmago de processos, cuja análise é exigida pela reflexão do anonimato.

Afinal, o anonimato não é um fenômeno de simples delimitação. Ao contrário, trata-se de um fenômeno móvil e, ao mesmo tempo, articulado a seletividades e imobilizações sociais profundas. A título de indicação da complexidade envolvida, citamos, em seqüência ao realizado por Céli Regina Jardim Pinto (2000) com relação à tolerância, as definições propostas pelo Dicionário Houaiss da Língua Portuguesa para anônimo:

1- que não tem o nome ou a assinatura do criador, sem autoria; 2- que ou aquele que não revela o seu nome; 3- que ou que é obscuro, desconhecido: que ou o que não tem nome ou renome. Etim. gr. - anônumos: sem nome, que não recebeu nome, inominado, que não se deve ou não se pode nomear (nome tabu, como o das Fúrias), abominável, indigno, que não se faz conhecer, desconhecido, obscuro, sem glória. (Houaiss, 2001). 
Por estas definições, fica claro que nomear o anônimo compreende algo de sacrílego e, também, de necessariamente violento, já que a palavra proposta, em qualquer caminho analítico ou estrutura discursiva, envolverá, sempre, um ato exterior ao que está sendo nomeado. Esta violência é a mesma que existe, sem grandes alardes, no uso corrente da noção de excluído. Acreditamos, neste sentido, que não é à toa que a referência aos Sem Terra é mais usual, na grande imprensa, do que a referência a Trabalhadores Rurais Sem Terra, onde uma identidade positiva, e com projeto, qualifica a carência, a falta, o não-ter. Por outro lado, "o que não tem nome" aproxima-se do inclassificável e, portanto, do que é inacessível à ciência. O discurso analítico, neste terreno de questões, aproxima-se, perigosamente, do discurso autoritário.

Nesta direção, Octávio Ianni chama a atenção para a ânsia do homem moderno pela nomeação. Esta ânsia expressaria a sua vontade de dominar a existência e de controlar a sua insegurança e incerteza, inclusive a que advém do abandono do divino. Na vontade de nomear, esconde-se, para o autor, o mito da transparência mas, também, e esta é uma bela abertura para a continuidade das ciências sociais, o inelutável encanto e a sedução da palavra, reunidos no eterno refazer da vida social. Entretanto, este encanto convive com a dialética permanente entre palavra e silêncio e, acrescentamos com Foucault (1996), entre palavra e regras do silenciamento:

Aos poucos, ao longo do tempo e conforme a dinâmica das configurações histórico-sociais, tudo tende a adquirir nome, movimento, tensão e significado, ou vida. O nome, o conceito ou a metáfora pode ser um momento essencial, constitutivo, sem o qual nada se configura como existência, ser, devir (...). Há momentos (porém) em que a língua emudece, seja porque não há o que dizer, seja porque nada é necessário dizer ou, ainda, porque não há como dizer. (Ianni, 2000, p. 214-215).

Pelas orientações analíticas trazidas por Octávio Ianni, evidenciase que a ausência de nomeação significa inexistência social. $\mathrm{O}$ anônimo é o oculto e o silenciado mas, sobretudo é, o inexistente, o que não foi ainda ou o que nunca será incluído no trabalho incessante, realizado pela sociedade, de produção do discurso e de novas categorias. Sem dúvida, a denúncia do desaparecimento do que não existe aproxima-se de uma fantasmagoria, ameaçando o denunciador com os epítetos de 
farsante ou insano. Torna-se indispensável, porém, defender que o inominado existe, em meio ao intenso exercício de produção de nomeações que impede o seu reconhecimento como desafio societário. ${ }^{2}$ Por outro lado, é indispensável resistir aos mecanismos sociais reprodutores de anônimos e, assim, às formas de controle e enfraquecimento, tão atuais, da interação social (Egler, 2000), dos gestos espontâneos e da descoberta, sempre ousada, de infinitos outros.

\section{Sobre o nada e o ninguém}

Como recorda a epígrafe deste texto, o corpo, visto como pura matéria, transforma-se em dejeto. Não é sequer número. Não merece choro, túmulo, flores ou vela - nem cantos nem prantos, apenas resto. ${ }^{3}$ O escravo não é nem indivíduo e nem pessoa. Assim, o seu corpo sem vida transforma-se no nada do lixo, afastado da identidade na morte, como o foi em vida. O país dos sem nome, nem bens, tem raízes profundas, construídas pelos processos que configuraram o anonimato, que é, ao mesmo tempo, estrutural e estruturante.

A ênfase no corpo, que no presente absorve tantos investimentos mercantis, anuncia o predomínio da morte sobre a vida, na medida em que coaduna-se com a tendência, denunciada por Alain Badiou (1995), à anulação da face imortal dos seres humanos, aquela que só pode ser reconhecida através do inesperado, do irredutível e do absolutamente surpreendente das verdades em processo, inscritas nos movimentos de vida e, não, de morte. A ênfase no corpo também corresponde ao empobrecimento da elaboração simbólica da própria morte. Nas palavras de Michel Vovelle:

Hoje, poderíamos dizer que, se mal sabemos a que santo rezar, menos ainda (sabemos) a que base visual nos devotar. É certo que o cemitério já não é (...) o lugar onde se podiam ler as expressões coletivas do imaginário diante da morte (...). Entrementes, nos assalta toda uma torrente de imagens, da história em quadrinhos ao cinema e à televisão, como expressões ambíguas de uma morte ao mesmo tempo manifesta e oculta, em nossa época permeada pelo tabu da morte. (Vovelle, 1997, p. 29).

A fragilização da vida social, manifesta no tabu da morte, atinge os sem documento e registro, consolidando as camadas demográficas 
do que Boaventura Santos (1999) anunciou como passagem direta do pré-contratualismo ao pós-contratualismo. O contrato da escravidão, desenhado nas mediações econômicas da exploração colonial, aconteceu, sim, mas apenas entre compradores e negociadores de energia humana desapropriada de forma total. Esta herança do nada e do ninguém atualiza-se em múltiplas relações hierárquicas que particularizam a formação social brasileira mas, também, através de processos que transformam a pessoa ou o indivíduo em feixe de diferentes capacidades de trabalho, eventualmente úteis à condução neutra, objetiva e maquínica dos mercados.

À cegueira do passado soma-se a cegueira racionalizada do presente, impedindo que a questão da identidade adquira, no país, a sua conotação social e politicamente afirmativa. Como reconhecer a existência de outros, como anseia a denominada ética da diferença, se estes são invisíveis ou apenas vistos como objeto e paisagem ou, como propõe a nova administração, como um conjunto de características decompostas e apropriadas pela dinâmica da economia? Como reconhecer a violência da diferença radical que se constitui através do não-outro e do nada, através de interações sociais cada vez mais rápidas e descartáveis, que não permitem a troca e a compreensão? Como respeitar a integridade do outro, que inclui os processos únicos que constróem a subjetivação e a identidade, quando este nada mais é do que o anônimo: perigoso, exótico ou consumível? ${ }^{4}$

Em verdade, o respeito à diferença como condução máxima da ética contemporânea - que, para Alain Badiou, realiza-se, em grande parte, como ideologia - acontece sobre um tecido social que expande a invisibilidade, num período marcado pelo império da imagem, ou que reconhece, apenas, a diferença já controlada e, logo, considerada legítima: "Poderia dar-se que (...) a ideologia ética não seja senão a última palavra do civilizado conquistador: 'Torna-te como eu e respeitarei tua diferença"” (Badiou, 1995, p. 39). Esta condução limitada da ética, que organiza determinadas interações sociais e nega outras, exige o exame permanente da tensão entre diferença e indiferença, e não somente, como propõem os críticos dos códigos dominantes da governabilidade, entre diferença e igualdade. 
Aliás, é a defesa intransigente do direito à igualdade que exige em sua dinâmica prática, ao nosso ver, a consideração da passagem diferença $\Leftrightarrow$ indiferença, oculta pelo uso corrente, crescentemente ágil e banal, da oposição civilização-barbárie. Afinal, aos bárbaros, aos nãooutros, não cabe reconhecer cultura, identidade ou valores alternativos mas, somente, a substância do indiferente, que viabiliza o seu uso para finalidades que lhes são antagônicas ou a sua eliminação. $\mathrm{O}$ escândalo recente do número de mortos no Brasil, superior àquele da guerra do Vietnã ou do conflito entre israelenses e palestinos, diz bem dos fenômenos associáveis ao anonimato, alimentado e alimentador do desaparecimento.

Porém, mesmo o escândalo, que sintoniza a injustiça, não é capaz de expor, com clareza, a carga de indiferença que explica esse número e nem a torcida, piedosamente escondida, para que no contigente de desaparecidos permaneçam apenas os anônimos, "aqueles outros lá", simultaneamente tão distantes e tão próximos. ${ }^{5}$ De fato, a problemática contemporânea da integração social inclui o desafio maior representado pela ruptura das engrenagens sociais ${ }^{6}$ da invisibilidade. Esta problemática não se reduz, portanto, à gestão democrática dos recursos disponíveis, já que a gestão desejável enfrenta o desafio da dissolução, como afirma Agnes Heller (1999), dos poderes morais que poderiam conduzi-la.

A tendência à dissolução dos poderes morais é correlata da tendência à desinstitucionalização ${ }^{7}$ e, também, à desconstrução da meta moderna dos direitos generalizados e de plena afirmação do indivíduo $\Rightarrow$ sujeito (cidadão). No âmago do tecido urbano, tais tendências correspondem à manifestação do insulamento de segmentos sociais que, uma vez consolidado, resiste às tentativas de gestão democrática dos recursos. Por outro lado, são estes mesmos processos que surgem no empobrecimento das interações sociais, retendo a compreensão do eunós como verdadeira unidade do social, o eu em rede (e enredado), como proposto por Norbert Elias:

É possível que o indivíduo não conheça ninguém nesse burburinho (da cidade); mas, em algum lugar, ele tem pessoas a quem conhece, amigos de confiança e inimigos, uma família, um círculo de relações a que pertence, ou caso agora esteja só, tem conhecidos perdidos ou mortos que vivem em sua memória. (Elias, 1994, p. 21). 


\section{E, indagamos, será?}

A fragilidade crescente da interação social, aprisionada nos termos da equação tolerância $x$ intolerância, ${ }^{8}$ reforça os mecanismos reprodutores do insulamento, ampliando o espectro da indiferença. Afinal, não existe apenas vulnerabilidade. Existem, também, mecanismos sociais responsáveis pela vulnerabilização - percebida, temida e vivida. O anonimato se inscreve nestes processos como uma "mancha de óleo" de limites indefinidos, expressando a fragilização dos vínculos e redes sociais que constróem a pessoa sem que surjam as condições societárias de afirmação do indivíduo autônomo, com possibilidades de escolha dos valores que orientarão a sua luta por afirmação social plena. Assim, se há crise da modernidade, há, também, crise dos projetos de modernização, inclusive dos ideários que orientaram expectativas de transformação social geradas em torno da consolidação do capitalismo nas sociedades periféricas.

Entre a subordinação da pessoa, que se traduz em servilismo e dependência, e o fechamento de um mercado de trabalho altamente seletivo, o que pode ser esperado? É este dilema que Luiz Eduardo Soares reconhece na figura da empregada doméstica:

Do ponto de vista das empregadas domésticas, o desafio é elas se desvencilharem de seus próprios valores e práticas hierárquicos para lidar com o novo ambiente social. Entretanto, se isto é fácil de dizer, é difícil de fazer, e não apenas por motivos culturais e psicológicos, mas também por motivos micropolíticos, já que a linguagem da hierarquia é um instrumento para levar os empregadores na direção de uma espécie de acordo conciliatório entre o formalismo profissional individualista e as ligações pessoais. Quando alguém está ameaçado pela fome e pela pobreza extremas, qualquer negociação pode valer a pena, mesmo se o seu preço for o dano psicológico e a autoaniquilação. (Soares, 1999, p. 235).

A existência histórica do não-outro e a experiência da vulnerabilidade constituem um tecido social ambíguo e esgarçado, a partir do qual é travada a luta pela inclusão na hierarquia social e a resistência ao anonimato absoluto, aquele que configura a ameaça da eliminação. Desta maneira, o anonimato possui uma extensão alargada, que envolve desde a eliminação física até os bloqueios econômicos e 
culturais a qualquer movimento em direção à mobilidade social ascendente. ${ }^{9}$ Pode ser compreendido, portanto, como uma espécie de nebulosa societária, de um purgatório laico, onde é negociado e decidido o jogo da vida (e da morte).

De fato, o anonimato inscreve-se num espaço social indefinido, isto é, com as características de um purgatório, aquele "terceiro lugar" analiticamente valorizado por Michel Vovelle (1997). ${ }^{10}$ Este espaço se expande, na atualidade, de forma dessacralizada. Como sair do purgatório laico? Dois movimentos fundamentais organizam a dinâmica deste espaço. Através de uma ampla corrente de atos, manifesta-se a busca do encaixe social possível numa das ordens que, associadas e em mútua pressão, configuram a sociedade brasileira (Soares, 1999) - a tradicional, patrimonialista; e a moderna, mercantil. Noutra corrente, permanece a transumância brasileira, aquela que expressa a impossibilidade da sedentarização através do domicílio, da organização familiar, do círculo de vizinhança ou do trabalho.

Assim, do âmago do grande movimento de urbanização, associado à modernização, desdobram-se outros movimentos expressivos da existência do não-outro: nem proprietários nem trabalhadores, "sem lenço nem documento" (cf., para as migrações intra-metropolitanas, Jardim 2001). ${ }^{11}$ Estes não contam e nem são contados:

Genivaldo Lopes de Lima, 31 anos (...) ficou indignado ao saber que não foi contado no último recenseamento: 'Eu me sinto mal com isto. Esse país não dá oportunidade para ninguém'. O IBGE (...) não inclui 'pessoas errantes', sem domicílio fixo, na contagem dos habitantes (...) A maioria dos moradores de rua espalhados pelo país se enquadra nessa categoria. ("Invisível”, Revista Única, jan. 2000).

Sobre o não-outro, os anônimos ameaçados pelo desaparecimento, têm sido lançados, a partir da última década, diferentes holofotes. Para baixo, as políticas sociais focalizadas designam vulneráveis, criando áreas luminosas, também elas rigorosamente seletivas (Mendonça, 2000). $\mathrm{Na}$ implementação da política focalizada, racionalmente concebida e calculada, continuam os impasses com origem na amplitude estrutural e estruturante do não-outro. É este fato que pode ser exemplificado através de matéria jornalística recente: 
Os burocratas responsáveis pelo programa do governo federal (bolsaescola) se esqueceram das 'crianças-fantasmas' (cerca de 1 milhão) (...). 15 a $20 \%$ da população brasileira (...) nunca foi registrada ou perdeu a certidão. Esse é o cálculo do presidente da Associação Nacional de Cartórios (...). (Cães paulistanos ganham carteira de identidade, Jornal do Brasil, 16 fev. 2002). ${ }^{12}$

Em direção ao ápice social, cresce o número de empresas e profissões dedicadas a trazer os holofotes da mídia para aqueles que ambicionam "sair" do anonimato, atingindo a celebridade. A promoção da pessoa, um dos epicentros da indústria cultural, é similar aos investimentos empresariais em torno da personalização dos serviços, através dos quais a promessa do cidadão, como afirma Milton Santos (1987), se dissolve na figura do consumidor. ${ }^{13}$ Nesta direção, um interessante quadro, intitulado "A boca do funil", publicado pela revista Domingo ("Quero ser famoso", Jornal do Brasil, 24/2/02) apresenta dados relativos ao número de inscritos e de vagas em concursos promovidos pela mídia, vinculada à indústria da moda: Riachuelo Mega Model - 300.000 inscritas para 1 vaga; Top Model TV Globo - 100.000 para 1 vaga; Big Brother Brasil - 500.000 para 12 vagas; Chiquititas 120.000 para 20 vagas; Loura do É o Tchan - 2.500 para 1 vaga; Paquitas - 12.000 para 10 vagas; Garota Playboy Brahma - 1.000 para 3 vagas.

Tanto o foco para baixo como o foco para cima esclarecem os limites em que se realiza a meta moderna da integração social: nem modernização nem modernidade e, sim, inclusão circunstancial e competitividade construídas por engrenagens sociais racionalmente concebidas. Em ambos, manifestam-se características da ação hegemônica contemporânea, aquela que se caracteriza pelo cálculo, pela exatidão e pelo anseio da precisão absoluta (Ribeiro e Silva, 2002).${ }^{14}$ A própria idéia de foco implica numa aproximação semântica de nicho e oportunidade. A velocidade, esta característica do mundo moderno, atinge, de forma cada vez mais eficaz, o tecido social, selecionando e promovendo alguns segmentos e grupos sociais e, sobretudo, pessoas. Nas palavras do psicólogo Marco Antonio de Tommaso, das agências de modelo Elite e L'Équipe: “As pessoas saem do anonimato pela porta dos fundos. A maioria não tem uma profissão e 
não consegue se sustentar entre as celebridades por muito tempo" (revista Domingo, artigo citado). ${ }^{15}$

Em síntese, pode ser dito que a produção social contemporânea do anonimato decorre: a) da permanência de processos estruturais da formação social brasileira, originados da colonização, da escravidão e das formas dominantes de apropriação dos recursos; b) do apagamento de mecanismos tradicionais de reconhecimento da pessoa, decorrente da destruição de modos de vida; c) dos limites da afirmação do indivíduo (sujeito $\Rightarrow$ cidadão) frente aos caminhos tomados pela modernização econômica e social; d) do crescente agenciamento administrativo e/ou mercantil de formas, circunstanciais e limitadas, de construção de presenças sociais. Com relação a este último conjunto de processos, seria correto dizer que o agenciamento é distante, por suas características estratégicas, dos mecanismos de reconhecimento da pessoa que organizam as sociedades tradicionais, seja para a alocação de privilégios excepcionais no âmago das classes dominantes, como indicam o familismo e o nepotismo, seja para que a vida seja possível para as classes populares.

\section{Segunda abertura: sobre classificações}

Durkheim e Mauss (1981), no ensaio clássico sobre as formas primitivas de classificação, evidenciaram o envolvimento de todas as classificações, inclusive as científicas, com as formas de organização da vida social. Não possuímos, depois deste ensaio, o direito a recorrer a um escudo de verdades objetivas, transhistóricas, que garanta o afastamento das nossas práticas de conhecimento daquelas que organizam a experiência coletiva. As categorias analíticas, assim como as metáforas, estão prenhes das formas predominantes de compreensão do mundo. Aliás, como afirma Foucault (1982), existem inequívocos efeitos de poder na ordenação do conhecimento proposta por diferentes disciplinas.

Também Bourdieu (1989) desvendou as lutas políticas envolvendo prestígio e acesso a recursos - que constróem argumentos científicos, o que impede que, neles, possam ser reconhecidos somente conteúdos maiores ou menores de uma verdade objetiva, externa aos campos que conformam a vida social e, por conseguinte, à possibilidade 
de conhecimento. Nas problemáticas científicas e nos códigos de conduta, intensamente veiculados, escondem-se relações de poder que visam instituir o outro legítimo e controlar a existência do não-outro. É nesta direção que pode ser compreendida a seguinte advertência de Céli Regina Jardim Pinto, (2000, p. 34) relativa à idéia de tolerância: "Alguém sempre tem o poder de definir o que ou qual é a medida que será tolerada (...) A tolerância pensada em termos políticos pode levar à perigosa idéia do mal menor, da abertura limitada à presença do outro, deixando intacta a fronteira entre quem tolera e quem é tolerado, o segundo não modifica o primeiro".

Consiste um exercício esclarecedor a reflexão dos mecanismos de poder que orientam os investimentos de diferentes instituições (por exemplo organismos governamentais e agências multilaterais) em direção ao encontro do nome consensual do não-outro. Sem dúvida, a crise do mundo do trabalho atinge as práticas classificatórias que ordenaram, até recentemente, relações e expectativas sociais, tais como: trabalhador, pobre, bom filho e pai de família. A dissolução destas categorias não é total e absoluta. Ao contrário, existe uma luta surda por sua preservação, o que se manifesta na força contemporânea do discurso religioso ${ }^{16}$ e naqueles discursos políticos que buscam legitimar reivindicações sociais e reduzir os riscos da eliminação. Entre as categorias novos-pobres, moradores de rua, traficantes e, até mesmo, terroristas passam diferentes linhas institucionais que configuram, diariamente, uma rede de sentidos e representações sociais que iluminam e ocultam o não-outro, refazendo a experiência do anonimato.

Tentar encontrar, neste momento, uma boa e justa forma de classificação do não-outro, desfazendo simbolicamente o anonimato a partir dos instrumentos das ciências sociais, seria negar a existência do invisível. Cairíamos, por este caminho, numa armadilha dos sentidos, que terminaria por negar o que desejamos, pelo menos, reconhecer: o anonimato estrutural e estruturante com origem tanto em desinvestimentos sociais como nos limites estabelecidos por investimentos estratégicos.

Também não se trata, aqui, de rever criticamente classificações, mas de observar que estas tangenciam o fenômeno da produção social do anonimato. Afinal, a própria socialidade é limitada e, portanto, as 
classificações a que dá origem. Isto significa dizer, o que de início parece absurdo, que o próprio tecido social é um "cobertor curto". A destinação ao invisível manifesta-se no seguinte trecho da matéria da revista Única, antes citada: "Protegida por um cobertor cinza que deixa só seus cabelos brancos à mostra, Gerassina Ferreira Sampaio, 56 anos, parece se fundir com o muro do cemitério da Consolação, região central de São Paulo, onde "mora"'. Ainda nesta reportagem, há a referência à categoria "selvagens urbanos", uma categoria discursiva do não-outro, que considerariam "como inimigos seus os demais habitantes da cidade (...) ( 'optando') por lugares onde não chamam a atenção".

Frente aos processos que conformam o fenômeno da produção social do anonimato, precisariam ser criadas e inventadas mediações e interações, produzindo um verdadeiro alargamento de cada ponto de vida social ativa. Há carência de um excesso de "vontade de sociedade" para que ocorra a redução do não-outro. A única possibilidade de não reproduzir as ameaças associadas ao anonimato encontra-se na ruptura radical das categorias que buscam controlá-lo, inclusive aquelas do pensamento crítico. O não-outro não pode ser nomeado por sua carência, já que esta é conformada pelo vazio societário, mas, apenas, a partir da interação aberta, perseverante e tentativa ao mesmo tempo. Como diz a psicóloga Aparecida Magali Álvarez, também citada no artigo da revista Única: "O fato de alguém conversar, olhar nos olhos deles, é importante para eles".

As classificações atuais, calcadas em geral nas noções de excluído ou vulnerável, criam de imediato uma substância para o não-outro, constituindo uma formulação controlável, segundo a orientação de Alain Badiou (1995), do todo-outro. Este todo-outro, para nós, emerge: a) da identidade construída pela carência escolhida pelas políticas públicas; b) do discurso religioso que institui a interação legítima, ditada pela "boa consciência"; c) da categoria generalizante e não interativa, como realizado tantas vezes pelas ciências sociais; d) dos focos oscilantes da mídia, das políticas públicas e de ações desenvolvidas por um grande número de instituições (por exemplo igrejas e ONGs).

Na realidade, além dos processos relacionados à produção social do anonimato, deveríamos fazer referência a outros fenômenos societários, que também respondem pela crise da política e dos projetos 
de integração social. Entre estes fenômenos, caberia citar, por sua estreita relação com a invisibilidade e o desaparecimento, a tendência ao predomínio das relações passivas sobre as relações ativas, e verdadeiramente intersubjetivas, o que não contradiz uma outra tendência, aquela da transformação da ação social num permanente ativismo. Nas palavras de Boaventura Santos:

A mesma transformação constante de perspectiva (aquela do mercado) está ocorrendo nas tecnologias de informação e comunicação, onde aliás a turbulência das escalas é o ato originário e a condição de funcionalidade. Aí a crescente interatividade das tecnologias dispensa cada vez mais a dos utilizadores e, por essa via, a interatividade desliza subrepticiamente para a interpassividade. (Santos, 1999, p. 42).

Estas tendências manifestam o esgotamento de sonhos e utopias da modernidade e, entre eles, o anonimato com encanto, associado aos mistérios da vida na grande cidade e à ruptura das formas primárias de controle social. Como afirma Agnes Heller (1999, p. 21) "Viver na incerteza é traumático. Viver na incerteza de significados e valores ainda mais. Um trauma tem consequiências psicológicas - e, através de mediações, sociopáticas - perigosas. O trauma moderno não é um acontecimento, mas um estado de coisas, pois é contínuo". ${ }^{17}$ O que significa a transformação do anonimato voluntário no involuntário, na ausência de contrato social (Santos, 1999) e, de forma mais grave, de pactos sociais (Pellegrino, 1989)?

A ausência de pactos implica em ausência de socialidade, das fibras, nós e pontos que conformam os desenhos do tecido social. Escolher enfatizar, ao final deste texto, mais uma vez, os elos entre anonimato e invisibilidade: "Quando Maria falou "vamos passar para a sala' levei um susto. Via apenas um papelão e, perto do muro, jornais e cobertores. Estava em pé sobre a sua cama, mas não havia percebido sua casa reproduzida no espaço da rua" (Jane Prates, assistente social de Porto Alegre, citada no artigo da revista Única). Escolhemos, por fim, retornar ao tema da intolerância nas palavras de José Saramago (1997, p. 520) "Continuaremos a ser intolerantes porque não queremos compreender que não basta ser tolerante. Enquanto formos incapazes de reconhecer a igualdade profunda de todos os seres humanos não sairemos da desastrosa situação em que nos encontramos". 


\section{Notas}

1 Como indica Howard Becker, através de citação de artigo de Johan Galtung em que este autor alerta para a necessidade de reflexão de como a forte estratificação social afeta a Sociologia latino-americana: "Advém daí o grande interesse pela alienação das classes mais baixas: sem negar sua realidade, um fator que mantém a imagem de alienação da classe trabalhadora é a alienação do próprio intelectual em relação à sua sociedade em geral e, certamente, em relação à classe trabalhadora" (Galtung, 1965, p. 65 apud Becker, 1999, p. 112).

2 Nesta direção, cabe registrar que o sociólogo Mário Hélio Trindade de Lima desenvolve, no IPPUR/UFRJ, tese de doutorado sobre as práticas classificatórias que organizam o discurso da exclusão, com título provisório de "Os excluídos: discursos sobre a pobreza urbana no Brasil". Ver também Lima, (1998).

3 Em texto recente (2002), registramos significados da morte de amigos para jovens populares do Rio de Janeiro. Estes amigos, envolvidos com o tráfico, não podiam ser pranteados e nem valorizados, por se constituírem em exemplos contemporâneos da morte anunciada e indigna. Recordá-los significaria correr riscos ou, de alguma forma, ser solidário nos caminhos que percorreram em vida. Também devemos registrar outro episódio nesta mesma direção. Num dia qualquer, vimos um cadáver com as pernas na pista de acesso à cidade universitária. Tentando conversar com algumas pessoas sobre o fato, observamos que estranhavam o choque e revolta manifestos nas palavras que utilizávamos. Alguém, inclusive, indagou: "Tem algum problema em sua casa?".

4 Basta lembrar, nesta direção, o denominado turismo sexual e a expansão da pedofilia. São múltiplos, de fato, os caminhos para a objetivação, utilitarista e destrutiva, do outro. Como afirma Jurandir Freire Costa: "Como (...) seduzir, conquistar, convencer os indivíduos de que (...) esse sistema em que vivemos 'é o melhor, o mais avançado, o mais moderno, o mais desejável?'. A solução foi persuadir os indivíduos de que nesse sistema temos possibilidades de ter 'mais prazer, mais excitação, mais êxtases cotidianos' do que em qualquer outro conhecido" (entrevista realizada por Anabela Paiva: "Sexo é mercadoria", Jornal do Brasil, 13 mar. 2002).

5 "Nesse pathos do próximo se advinha o tremor equívoco, situado entre o medo e o prazer, ao perceber o horror e a destruição, a guerra e o cinismo enfim bem perto de nós. A ideologia ética dispõe, quase à porta do abrigo civilizado e seguro, da combinação revoltante e deliciosa entre um Outro confuso (croatas, sérvios e esses enigmáticos 'muçulmanos' da Bósnia) e 
um Mal evidenciado. Os alimentos da ética nos são servidos a domicílio pela História” (Badiou, 1995, p. 47).

6 “Às vezes se diz que o oposto de uma verdade profunda é outra verdade profunda. As ciências sociais oferecem várias ilustrações dessa verdade profunda. Podem isolar tendências, propensões e mecanismos, e mostrar que têm implicações freqüentemente surpreendentes e contra-intuitivas para o comportamento. $\mathrm{O}$ que só mais raramente são capazes de fazer é estabelecer condições necessárias e suficientes sob as quais os vários mecanismos são postos em funcionamento" (Elster, 1994, p. 24).

7 A desinstitucionalização se faz acompanhar pela concentração do não-outro em determinadas instituições, tais como os presídios e os asilos, como ilustra a matéria de Cynthia Garda, "Abandono em asilo revolta deputados" (Jornal do Brasil, 18 mar. 2002), da qual retiramos o seguinte depoimento do Deputado Marcos Rolim (PT/RS): "Mesmo depois de caravanas em presídios, manicômios e Febems, o que vimos foi absolutamente impactante (...) Os asilos são instituições do abandono". A matéria ainda permite saber que a CPI do Idoso, da Assembléia Legislativa do Estado do Rio de Janeiro, visitou 129 instituições e, destas, apenas 11 foram aprovadas e, ainda, que, do total, 77 estavam superlotadas. Nas palavras de Carlos Lessa: "Neste contexto de contra-revolução conservadora, quando o capital não reconhece nem mesmo os direitos dos que ainda trabalham, o problema do idoso adquire nuanças de perversidade impressionante.” (1998, p. 108).

8 Como afirma Maria Lúcia Karan, no artigo "A esquerda vai para a direita" (Jornal do Brasil, 4 fev. 2002, p. 9): "Épocas de desequilíbrio econômico e social, como o momento histórico atual, (...) trazem maior punição e não, necessariamente, (...) um aumento na quantidade de crimes. São épocas em que é mais necessário exibir o terror oficial, para que, sob o pretexto de repressão ao crime, sejam contidos movimentos transformadores. Sentimentos de medo e insegurança são manipulados, de forma a produzir preocupações crescentes com a criminalidade. Geram-se, assim, uma demanda de maior repressão e uma maior receptividade para a enganosa publicidade que 'vende' o rigor penal como solução."

9 Ermínia Maricato (2001, p. 34) cita estudo realizado pelo Programa de Aprimoramento das Informações de Mortalidade do Município de São Paulo que permitiu, ao pesquisador Marcos Drumond Júnior, reconhecer que "cinco regiões da cidade concentraram 52\% dos homicídios entre 1994 e 1998. Nelas, a maior parte das mortes se deram em favelas".

10 Michel Vovelle (1997) aponta para a relevância do período da segunda metade do século XV e o início do século XVI em relação ao inferno e ao purgatório. 
Seria interessante refletir como o advento da modernidade alarga a negociação que fundamenta a própria idéia de purgatório.

11 Ermínia Maricato (2001, p.35) também cita pesquisa realizada pelo LABHAB-FAU/USP em favelas de cinco cidades brasileiras. Esta pesquisa permitiu evidenciar que "um número significativo de pessoas (...) permanecem ociosas a maior parte do tempo no interior desses núcleos residenciais. Aí, em geral, o desemprego é maior. O número de pessoas por domicílio também. Não estamos longe da configuração de gueto que é reforçada pelo alto custo e baixa qualidade dos transportes."

12 Como sabemos, expande-se, na atualidade, a tendência à substituição das políticas públicas generalizadas por políticas compensatórias. Dificilmente, porém, assistimos a um debate público do que está sendo compensado. Em países com larga tradição em políticas afirmativas, como é o caso dos Estados Unidos, a compensação pode incluir fatos históricos profundos, como exemplificam as ações que visam a compensação da escravidão.

13 É através do predomínio da figura do consumidor que acontece a difusão de idéias que articulam o nome ao mercado, tais como as seguidas referências a "sujar" e "limpar" o nome nas instituições de controle do crédito.

14 Além dos cálculos da linha da pobreza, seria interessante recordar aqui os processos de recadastramento, implementados com relação ao usufruto de direitos adquiridos. $\mathrm{O}$ caráter ameaçador destes procedimentos inscreve-se na fronteira que separa os que tem nome - "estão na lista" - e os que desaparecem na massa, sem forma nem fôrma, de anônimos. Estes procedimentos, generalizados, indicam o peso crescente do jogo e da fortuna nos mecanismos de integração social.

15 Com relação sistema da moda, ver Henri Léfèbvre (1984). Também, com relação à moda, afirma Carlos Lessa (1998, p. 109): "O ato de adquirir o objeto é autodestrutivo, pois o objeto da moda entra em obsolescência no ato da aquisição. $\mathrm{O}$ valor de uso se deslocou, patologicamente, da mercadoria para o ato de aquisição. No mundo instantâneo, em que mercadoria não é mais colecionável, a analogia do envelhecer com perder o valor é imediata."

16 Com Giacomo Marramao (1997), aprendemos os limites da secularização e da dessacralização que se manifestam no próprio âmago da modernidade radicalizada.

17 A autora elabora a sua reflexão da modernidade com base em contrastes entre modernidade e pré-modernidade, salientando a tradição rompida, sem retorno, das sociedades pré-modernas, onde se inclui a cultura que organiza 
as hierarquias sociais. Entretanto, é sempre indispensável reconhecer que, nas sociedades de origem colonial e escravocrata, esta hierarquia desconhece o não-outro, o não hierarquizável.

Abstract. This essay inquiries about the current forms of social classification used to organize interventions towards the so-called "excluded". It analyzes the social production of the anonymous, emphasizing the social meanings of the focused strategic actions that characterize public policies and the competitiveness between economic actors. Philosophical and sociological frameworks and a heterogeneous collection of documents orient the discussion. This work alerts to the contemporary limits of the social relationships and the authoritarianism, hidden in the current forms of categorizing the "no-one".

Resumé. Le text interroge l'actuelle crise sociétaire, considérent ses liaisons avec les formes de nomméation et de classification social que organizent les interventions dirigéés aux "exclus". Se dirige, particulièrement, à la production sociale du anonymat et aux résultantes sociaux de l'action stratégique focalisée, caracteristique des politiques publiques et de la compe titivité entre des agents économiques. Avec ces objectives, le text s'appuie sur oriéntations reflexives de la philosoplie et de la sociologie et un ensemble de documents divers. L'article fait appel de l'attention pour les limites contemporains de la socialité et l'autoritarisme que se cachent sous les formes courrentes de noméation de le "non-autre".

\section{Referências bibliográficas}

BADIOU, Alain. Ética: um ensaio sobre a consciência do mal. Trad. Antônio Transito e Ari Roitman. Rio de Janeiro : Relume-Dumará, 1995.

BARSTED, Leila Linhares. Sobre ocultamentos, metáforas e banalizações. Proposta, n. 87, set./nov. 1999.

BECKER, Howard S. Métodos de pesquisa em ciências sociais. Trad. Marco Estevão e Renato Aguiar, rev. técnica de Márcia Arieira. 4. ed. São Paulo: HUCITEC, 1999.

BOURDIEU, Pierre. O poder simbólico. Lisboa : DIFEL, 1989.

DURKHEIM, Émile; MAUSS, Marcel. Algumas formas primitivas de classificação: contribuição para o estudo das representações coletivas. 
In: MAUSS, Marcel. Ensaios de Sociologia. São Paulo : Perspectiva, 1981. (Data original da coletânea: 1968).

EGLER, Tamara Tania Cohen. Interação social no espaço urbano: encontro ou confronto. In: RIBEIRO, Ana Clara Torres (Org.). Repensando a experiência urbana da América Latina: questões, conceitos e valores. Buenos Aires: CLACSO, 2000.

ELIAS, Norbert. A sociedade dos indivíduos. Trad. Vera Ribeiro, rev. técnica e notas Renato Janine Ribeiro. Rio de Janeiro : Zahar, 1994.

FOUCAULT, Michel. Microfísica do poder. Org. e trad. Roberto Machado. Rio de Janeiro : Graal, 1982. Cap. XI - Sobre a geografia.

. A ordem do discurso (aula inaugural no Collège de France, pronunciada em 2 de dezembro de 1970). Trad. Laura Fraga de Almeida Sampaio. São Paulo : Loyola, 1996.

GALTUNG, Johan. Los factores socioculturales y el desarrollo en la Sociología en América Latina. Revista Latinoamericana de Sociología, n. 1, mar. 1965.

HELLER, Agnes. Uma crise global da civilização: desafios futuros. In: HELLER, Agnes et al. A crise dos paradigmas em ciências sociais e os desafios para o século XXI. Rio de Janeiro : Contraponto, 1999.

IANNI, Octávio. Enigmas da modernidade - mundo. Rio de Janeiro : Civilização Brasileira, 2000.

JARDIM, Antônio. Mobilidade intrametropolitana: o caso do Rio de Janeiro. Rio de Janeiro, 2001. Tese (Doutorado) - IPPUR/UFRJ.

LÉFÈBVRE, Henri. A vida cotidiana no mundo moderno. Trad. Alcides João de Barros. São Paulo : Ática, 1991. (Edição original publicada em 1968).

LESSA, Carlos. O idoso como solução. Democracia Viva, n. 2, fev. 1998.

LIMA, Hélio. Cidade de papelão: mocós, cachangas e malocas. Vitória : EDUFES, 1998.

MARICATO, Ermínia. Brasil, cidades: alternativas para a crise urbana. Petrópolis (RJ) : Vozes, 2001.

MARRAMAO, Giacomo. Céu e terra: genealogia da secularização. Trad. Guilherme Alberto Gomez de Andrade. São Paulo : Fundação Editora UNESP, 1997.

MENDONÇA, Eduardo. A pobreza no Brasil: medidas e sentidos. Rio de Janeiro, 2000. Dissertação (Mestrado) - IPPUR/UFRJ. 
PELLEGRINO, Hélio. A burrice do demônio. Rio de Janeiro : Rocco, 1989.

PINTO, Céli Regina Jardim. Para além da tolerância. Caderno CRH, n. 32, jan./ jun. 2000.

RIBEIRO, Ana Clara Torres; LOURENÇO, Alice. A atualização da cidade: imagens, violência e classes sociais. In: ENCONTRO DO PROGRAMA DE PÓS-GRADUAÇÃO EM ARTES VISUAIS, 8. [Anais]. Rio de Janeiro : Escola de Belas Artes da UFRJ, 2001.

. Marcas do tempo: violência e objetivação da juventude. In: FRAGA, Paulo (Org). Juventude e sociedade. Rio de Janeiro: DP \& A, 2002. No prelo - título provisório.

RIBEIRO, Ana Clara Torres; SILVA, Cátia Antônia da. Impulsos globais e espaço urbano: sobre o novo economicismo. In: RIBEIRO, Ana Clara Torres (Org). O rosto urbano da América Latina. Buenos Aires : CLACSO, 2002. No prelo.

SANTOS, Boaventura de Souza. Reinventar a democracia: entre o précontratualismo e o pós-contratualismo. In: HELLER, Agnes et al. A crise dos paradigmas em ciências sociais e os desafios para o século XXI. Rio de Janeiro : Contraponto, 1999.

SANTOS, Milton. O espaço do cidadão. São Paulo : Nobel, 1987. A natureza do espaço: técnica e tempo, razão e emoção. São Paulo : HUCITEC, 1996.

SARAMARGO, José. Cadernos de Lanzarote. São Paulo : Companhia de Letras, 1997.

SOARES, Luiz Eduardo. A duplicidade da cultura brasileira. In: SOUZA, Jessé de (Org.). O malandro e o protestante: a tese weberiana e a singularidade cultural brasileira. Brasília : Editora da Universidade de Brasília, 1999.

VOVELLE, Michel. Imagens e imaginário na história: fantasmas e certezas nas mentalidades desde a Idade Média até o século XX. São Paulo : Ática, 1997. 